\title{
Serum vitamin D levels, diabetes and cardio-metabolic risk factors in Aboriginal and Torres Strait Islander Australians
}

Louise J Maple-Brown 1,2*, Jaquelyne T Hughes ${ }^{1,2}$, Zhong X Lư ${ }^{3,4}$, Kanakamani Jeyaraman ${ }^{1,5}$, Paul Lawton ${ }^{1}$, Graham RD Jones ${ }^{6,7}$, Andrew Ellis ${ }^{8,11}$, Ashim Sinha ${ }^{9}$, Alan Cass ${ }^{1}$, Richard J Maclsaac ${ }^{10,11}$, George Jerums ${ }^{8,11}$ and Kerin $\mathrm{O}^{\prime} \mathrm{Dea}^{5}$

\begin{abstract}
Background: Low levels of serum 25-hydroxy vitamin D $(25(\mathrm{OH}) \mathrm{D})$, have been associated with development of type 2 diabetes and cardiovascular disease (CVD); however there are limited data on serum 25(OH)D in Indigenous Australians, a population at high risk for both diabetes and CVD. We aimed to assess levels of serum 25(OH)D in Aboriginal and Torres Strait Islander Australians and to explore relationships between 25(OH)D and cardio-metabolic risk factors and diabetes.

Methods: 592 Aboriginal and/or Torres Strait Islander Australian participants of The eGFR (estimated glomerular filtration rate) Study, a cross-sectional analysis of a cohort study performed in 2007-2011, from urban and remote centres within communities, primary care and tertiary hospitals across Northern Territory, Far North Queensland and Western Australia. Assessment of serum 25(OH)D, cardio-metabolic risk factors (central obesity, diabetes, hypertension, history of cardiovascular disease, current smoker, low HDL-cholesterol), and diabetes (by history or $\mathrm{HbA} 1 \mathrm{c} \geq 6.5 \%$ ) was performed. Associations were explored between $25(\mathrm{OH}) \mathrm{D}$ and outcome measures of diabetes and number of cardio-metabolic risk factors.

Results: The median (IQR) serum 25(OH)D was $60(45-77) \mathrm{nmol} / \mathrm{L}, 31 \%$ had $25(\mathrm{OH}) \mathrm{D}<50 \mathrm{nmol} / \mathrm{L}$. For participants with $25(\mathrm{OH}) \mathrm{D}<50 \mathrm{vs} \geq 50 \mathrm{nmol} / \mathrm{L}$, cardio-metabolic risk profile differed for: diabetes (54\%, 36\% p < 0.001), past history of cardiovascular disease $(16 \%, 9 \%, p=0.014)$, waist-hip ratio $(0.98,0.92, p<0.001)$, urine albumin-creatinine ratio $(2.7,1.5 \mathrm{mg} / \mathrm{mmol}, \mathrm{p}<0.001)$. The OR $(95 \% \mathrm{Cl})$ for diabetes was $2.02(1.03-3.95)$ for people in the lowest vs highest tertiles of $25(\mathrm{OH}) \mathrm{D}(<53 \mathrm{vs}>72 \mathrm{nmol} / \mathrm{L}$, respectively) after adjusting for known cardio-metabolic risk factors.

Conclusion: The percentage of 25(OH)D levels $<50 \mathrm{nmol} / \mathrm{L}$ was high among Aboriginal and Torres Strait Islander Australians from Northern and Central Australia. Low 25(OH)D level was associated with adverse cardio-metabolic risk profile and was independently associated with diabetes. These findings require exploration in longitudinal studies.
\end{abstract}

Keywords: 25-hydroxy vitamin D, Type 2 diabetes, Aboriginal, Cardiovascular risk

\footnotetext{
* Correspondence: louise.maple-brown@menzies.edu.au

1 Menzies School of Health Research, Charles Darwin University, Darwin,

Australia

${ }^{2}$ Division of Medicine, Royal Darwin Hospital, Darwin, Australia

Full list of author information is available at the end of the article
} 


\section{Background}

The major contributor to the significantly reduced life expectancy of Indigenous Australians, compared to the general Australian population is the overwhelming burden of chronic diseases, such as ischaemic heart disease, diabetes and chronic kidney disease [1]. Low levels of serum 25-hydroxy vitamin D $(25(\mathrm{OH}) \mathrm{D})$, the best marker for vitamin D status, have been associated with development of the metabolic syndrome [2], diabetes [3,4] and cardiovascular disease [5] in many parts of the world, but there are limited data on serum 25(OH)D levels in the high risk Indigenous Australian population.

Most available data on vitamin D deficiency in Australia relate to studies performed in the temperate zones. The Australian Diabetes, Obesity and Lifestyle (AusDiab) study reported that $31 \%$ of adults in Australia had serum 25 $(\mathrm{OH}) \mathrm{D}$ levels less than $50 \mathrm{nmol} / \mathrm{L}$, with a higher prevalence during winter-spring and in people residing in southern states [6]. Studies that have assessed vitamin D levels in groups such as the elderly [7], and free-living adults in Southeast Queensland (subtropical) [8] have demonstrated a prevalence of vitamin $\mathrm{D}$ deficiency (defined as serum 25(OH)D $<50 \mathrm{nmol} / \mathrm{L}$ ) of at least $25 \%$. However, small studies from the tropical region of Far North Queensland have reported a low prevalence of vitamin $\mathrm{D}$ deficiency in a healthy obstetric population (0\%) [9] and in free-living adults (6.2\%) [10]. Large population-based studies on vitamin $\mathrm{D}$ status are lacking in tropical Australia.

It is notable that the prevalence of vitamin D deficiency is higher in people with dark skin. A recent systematic review reported a prevalence of $30-53 \%$ in ethnic minorities with dark skin versus 14-26\% in those of Europid background [11]. Limited data from South Australia show that Indigenous Australians have a low vitamin D status [12]. However, approximately $40 \%$ of Indigenous Australians live at latitudes closer to the equator - in the tropical and subtropical regions of Australia [13]. In the context of high risk of premature mortality from cardiovascular disease and related chronic diseases in Indigenous Australians and the reported association between vitamin D and chronic diseases, further assessment of the vitamin D status and its relationship to cardio-metabolic risk factors in this high risk population is warranted.

Therefore, we evaluated the serum 25(OH)D levels in Aboriginal and Torres Strait Islander Australians in a cross sectional cohort of 592 Indigenous Australians from urban, regional and remote areas of the Northern Territory, Western Australia and Far North Queensland, participants in The Estimated Glomerular Filtration Rate Study (The eGFR Study) [14,15]. The aim of the eGFR Study was to assess the accuracy of estimated measures of glomerular filtration rate in Indigenous Australians. The aim of the current analysis is to assess levels of serum 25(OH)D in Indigenous Australians and to explore relationships between $25(\mathrm{OH}) \mathrm{D}$ and cardio-metabolic risk factors in this cohort.

\section{Methods \\ Participants}

The methods of the eGFR Study have been previously reported [14,15]. In brief, Aboriginal and/or Torres Strait Islander participants aged 16 years and above were recruited across five predefined strata of health, diabetes status and kidney function from the following regions of Australia: Top End, Northern Territory, Central Australia, remote Western Australia and Far North Queensland. The study was approved by the joint Menzies School of Health Research and Northern Territory Department of Health Human Research Ethics Committee (HREC) and other HRECs in the above regions [14].

Participants fulfilled the definition of 'Aboriginal and/or Torres Strait Islander' according to the standard method used in National Census data collection: "1) is of Aboriginal and/or Torres Strait Islander descent; 2) identifies as an Australian Aboriginal and/or Torres Strait Islander; and 3 ) is accepted as such by the community in which he or she lives or has lived." Of the 656 Indigenous participants of the eGFR Study, 605 had available data for serum 25(OH)D. Participants aged $<18$ years were excluded from this analysis $(n=13)$, leaving $n=592$ participants presented here. Participants of both Aboriginal and Torres Strait Islander background $(n=52)$ were combined with the Torres Strait Islander group as the two groups did not differ significantly for: age, body mass index (BMI), waist circumference, waist hip ratio (WHR), blood pressure (BP), HbA1c, lipid profile, urine albumin creatinine ratio (ACR), and serum 25(OH)D. The combined group of Torres Strait Islander participants and those of both Aboriginal and Torres Strait Islander background is referred to as Torres Strait Islander participants. This analysis includes 22 participants without data for measured glomerular filtration rate (mGFR), and participants missing data for other cardio-metabolic variables.

The latitude of participants' usual residence (Additional file 1: Figure S1) was [median, interquartile range (IQR), (range)]: Aboriginal participants, 16.4, 12.5-23.7 (11.235.1) degrees south, Torres Strait Islander participants $10.6,10.6-10.6$ (10.0-37.8) degrees south. Note that $66 \%$ (112 of 169) of Torres Strait Islander participants resided on Thursday Island at latitude 10.6 degrees south. The season of sampling was: Aboriginal participants, 5.4\% Summer (December-February), 28.6\% Autumn (March-May), 42.3\% Winter (June-August), 23.6\% Spring (SeptemberNovember); Torres Strait Islander participants, 42.0\% Summer, 4.7\% Autumn, 23.1\% Winter, 30.2\% Spring. 


\section{Laboratory methods}

The laboratory methods have been previously published [14]. In brief, urine albumin and creatinine, lipid profile (non-fasting) and HbA1c assays were performed at each centre by the local laboratory. The mGFR was measured using an iohexol plasma disappearance technique over 4 hours [14]. Serum high sensitive troponin T (hsTnT) and 25(OH)D were measured at Melbourne Pathology, Melbourne, Australia. Serum hsTnT was analysed using the electro-chemiluminescence immunoassay on a COBAS e601 analyser (Roche Diagnostics, Mannheim) with an inter-assay coefficient variation (CV) of $3.1 \%$. Serum $25(\mathrm{OH}) \mathrm{D}$ was analysed using the $25 \mathrm{OH}$ vitamin D TOTAL assay on a Liaison XL analyser (DiaSorin Inc., Stillwater, MN). It is an automatic, direct competitive chemiluminescent immunoassay with an inter-assay $\mathrm{CV}$ of $6.9 \%$ at $41 \mathrm{nmol} / \mathrm{L}$ and $5.8 \%$ at $101 \mathrm{nmol} / \mathrm{L}$. This method gives serum $25(\mathrm{OH}) \mathrm{D}$ results that align with the National Institute of Standards and Technology (NIST) targets. Compared to the NIST-aligned liquid chromatography-tandem mass spectrometry system, the equation obtained is y (Liaison $\mathrm{XL}$ in $\mathrm{nmol} / \mathrm{L}$ ) $=1.03 \times-$ $1.1[16]$.

\section{Cardio-metabolic risk factors}

Cardio-metabolic risk factors included components of the metabolic syndrome, using National Cholesterol Education Program, International Diabetes Federation and harmonised definitions [17]:

(a) Central Obesity: WHR $>0.9$ for males and $>0.85$ for females

(b)Diabetes: by history or HbA1c $\geq 6.5 \%$

(c) Low HDL-Cholesterol: $<1 \mathrm{mmol} / \mathrm{L}$ for males and $<1.3 \mathrm{mmol} / \mathrm{L}$ for females

(d)Hypertension: systolic BP $\geq 130 \mathrm{mmHg}$ or diastolic $\mathrm{BP} \geq 85 \mathrm{mmHg}$

(e) Current smoker: current cigarette smoker

(f) Past history of cardiovascular disease (CVD): history of ischaemic heart disease, acute myocardial infarction, cerebrovascular accident or transient ischaemic attack by self-report and/or medical records.

\section{Statistical methods}

Data analysis was performed using STATA v12.0 (Stata Corporation, TX, USA). Data are presented stratified by 25 $(\mathrm{OH}) \mathrm{D}$ levels $<50$ and $\geq 50 \mathrm{nmol} / \mathrm{L}$ (Table 1 ) as that is the cut-point used in national and international clinical guidelines. Variables with distributions significantly different from normal were $\log$ transformed. To determine between group differences, Pearson chi-square tests (categorical variables) or independent sample t-tests (continuous variables) were conducted. Due to missing data, $n$ of each group in Table 1 for the following variables was: BMI, 184 , 405; WHR, 172, 391; BP, 184, 402; Smoker, 183, 400; History CVD, 178, 387; HbA1c, 180, 394; HDL, 177, 381; mGFR, 176, 394; urine ACR, 183, 397. Cardio-metabolic risk factors were assessed in all participants and each ethnic group. The number of cardio-metabolic risk factors was calculated by counting how many of the following six factors were present: central obesity, low HDL-cholesterol, hypertension, diabetes, current smoker, and past history of CVD. Due to missing data, $\mathrm{n}$ of all participants and each group respectively in Table 2, for the following variables was: central obesity, 563, 398, 165; low HDL, 558, 402, 156; hypertension, 586, 419, 167; past history CVD, 565, 400, 165; current Smoker, 583, 417, 166; sum of CVD Risk Factors, 505, 358, 147. Distribution of $25(\mathrm{OH}) \mathrm{D}$ in participants with increasing number of cardio-metabolic risk factors was assessed graphically using a box plot (Figure 1). Logistic regression was used to estimate the odds ratio for participants in tertiles of serum 25(OH)D for two outcome variables: three or more cardio-metabolic risk factors (3+ cardio-metabolic risk factors) and diabetes. Models were performed using tertiles of 25(OH)D. Three models were performed for each outcome variable. Models 1 and 2 were the same for both outcome variables: model 1 was unadjusted; and model 2 adjusted for age, gender, ethnicity (Aboriginal or Torres Strait Islander), season and latitude. Different covariables were used in model 3. For the relationship between vitamin $\mathrm{D}$ and 3 + cardio-metabolic risk factors, model 3 was model 2 further adjusted for mGFR, troponin and urine ACR. For the relationship between vitamin $\mathrm{D}$ and diabetes, model 3 was model 2 further adjusted for WHR, HDL-cholesterol, mGFR, systolic blood pressure, current smoker, urine ACR. The fully adjusted models were constructed including covariates if they were clinically important or confounders. Tertiles of serum 25 $(\mathrm{OH}) \mathrm{D}$ were used in the multivariate modelling in order to perform a robust analysis of relationships between key variables, without an a priori decision as to where cut-points should be. For each outcome variable, two-way interactions were assessed between vitamin $\mathrm{D}$ and other independent variables in the model. There were no significant interaction terms.

\section{Results}

Of the 592 Indigenous participants, 423 (71\%) identified as Aboriginal and 169 (29\%) as Torres Strait Islander. The median (IQR) serum 25(OH)D was: all Indigenous participants, 60 (45-77) nmol/L; Aboriginal participants, 55 (40-70) nmol/L; Torres Strait Islander participants, 75 $(58-88) \mathrm{nmol} / \mathrm{L}$. Among all participants $(\mathrm{n}=592)$, the distribution of serum $25(\mathrm{OH}) \mathrm{D}<50,50-74$ and $\geq 75 \mathrm{nmol} / \mathrm{L}$ was $31 \%, 42 \%$ and $27 \%$ respectively. Participant characteristics, stratified by serum $25(\mathrm{OH}) \mathrm{D}<50$ or $\geq 50 \mathrm{nmol} / \mathrm{L}$, are presented in Table 1. A higher proportion of Aboriginal 
Table 1 Baseline characteristics stratified by serum 25(OH)D

\begin{tabular}{|c|c|c|c|}
\hline & $25(\mathrm{OH}) \mathrm{D}<50 \mathrm{nmol} / \mathrm{L}$ & $25(\mathrm{OH}) \mathrm{D} \geq 50 \mathrm{nmol} / \mathrm{L}$ & p value* \\
\hline$n$ & 186 & 406 & - \\
\hline Age (years) & $46(12)$ & $45(15)$ & 0.35 \\
\hline Aboriginal (\%) & $168(90 \%)$ & $255(63 \%)$ & \\
\hline Torres Strait Islander (\%) & $18(10 \%)$ & $151(37 \%)$ & $<0.001$ \\
\hline Male (\%) & 71 (38\%) & $150(37 \%)$ & 0.78 \\
\hline Current smoker (\%) & 77 (42\%) & $169(42 \%)$ & 0.97 \\
\hline Diabetes (\%) & $100(54 \%)$ & $148(36 \%)$ & $<0.001$ \\
\hline Past History CVD (\%) & $28(16 \%)$ & $34(9 \%)$ & 0.014 \\
\hline $\mathrm{BMI}\left(\mathrm{kg} / \mathrm{m}^{2}\right)$ & $30.5(7.1)$ & $29.5(7.3)$ & 0.15 \\
\hline Waist Hip ratio & $0.97(0.09)$ & $0.92(0.09)$ & $<0.001$ \\
\hline Systolic BP (mmHg) & $122(19)$ & $115(16)$ & $<0.001$ \\
\hline Diastolic BP (mmHg) & $77(11)$ & $73(10)$ & $<0.001$ \\
\hline $25(\mathrm{OH}) \mathrm{D}(\mathrm{nmol} / \mathrm{L})$ & $37(9)$ & $74(20)$ & $<0.001$ \\
\hline $\mathrm{HbA1c}(\%, \mathrm{mmol} / \mathrm{mol})$ & $6.3(5.9-7.8) 45(40-62)$ & $5.9(5.5-6.7) 41(37-50)$ & $<0.001$ \\
\hline HDL chol (mmol/L) & $1.0(0.8-1.2)$ & $1.1(0.9-1.3)$ & 0.29 \\
\hline Total chol: HDL chol & $4.5(3.6-5.8)$ & $4.4(3.6-5.7)$ & 0.21 \\
\hline Troponin $(\mu \mathrm{g} / \mathrm{L})$ & $3.0(3.0-5.2)$ & $3.0(3.0-5.7)$ & 0.10 \\
\hline $\operatorname{mGFR}\left(\mathrm{ml} / \mathrm{min} / 1.73 \mathrm{~m}^{2}\right)$ & $104(76-123)$ & $102(84-119)$ & 0.50 \\
\hline $\mathrm{mGFR}<60 \mathrm{ml} / \mathrm{min} / 1.73 \mathrm{~m}^{2}(\%)$ & $39(21 \%)$ & $63(16 \%)$ & 0.10 \\
\hline Urine ACR (mg/mmol) & $2.7(0.9-81)$ & $1.5(0.7-10)$ & $<0.001$ \\
\hline
\end{tabular}

Data presented as mean (standard deviation), median (interquartile range) or number (\%). $\mathrm{n}$ may vary due to missing data (see methods).

*Pearson chi-square test or independent sample t-test.

$p$ values $<0.05$ are represented in bold font.

participants had serum $25(\mathrm{OH}) \mathrm{D}<50 \mathrm{nmol} / \mathrm{L}$ than Torres Strait Islander participants. Compared to participants with serum $25(\mathrm{OH}) \mathrm{D} \geq 50 \mathrm{nmol}$, those with $25(\mathrm{OH}) \mathrm{D}$ $<50 \mathrm{nmol} / \mathrm{L}$ displayed a more adverse cardio-metabolic risk profile: higher percentage with diabetes and past history of
CVD; higher waist-hip ratio, blood pressure, HbA1c and urine ACR. The difference in urine ACR between groups with $25(\mathrm{OH}) \mathrm{D}<$ or $\geq 50 \mathrm{nmol}$ remained significant after adjustment for diabetes status $(\mathrm{p}=0.002)$ or HbA1c $(p=0.004)$.

Table 2 Number (\%) of Aboriginal and Torres Strait Islander participants with cardio-metabolic risk factors

\begin{tabular}{|c|c|c|c|c|c|c|}
\hline \multirow[t]{3}{*}{ Risk factor } & \multicolumn{2}{|l|}{ All participants } & \multicolumn{2}{|l|}{ Aboriginal } & \multicolumn{2}{|c|}{ Torres Strait Islander } \\
\hline & $n=592$ & & $n=423$ & & $n=169$ & \\
\hline & Male $(n==221)$ & Female $(n=371)$ & Male $(n==152)$ & Female $(n=271)$ & Male $(n=69)$ & Female $(n=100)$ \\
\hline Central Obesity & $163(76 \%)$ & $262(75 \%)$ & $116(79 \%)$ & $200(80 \%)$ & 47 (69\%) & $62(64 \%)$ \\
\hline Diabetes & $86(39 \%)$ & $162(44 \%)$ & $64(42 \%)$ & $121(45 \%)$ & $22(32 \%)$ & $41(41 \%)$ \\
\hline Low HDL* & $100(47 \%)$ & $249(72 \%)$ & $63(43 \%)$ & $185(72 \%)$ & $37(56 \%)^{* *}$ & $64(71 \%)$ \\
\hline Hypertension* & $69(32 \%)$ & $83(23 \%)$ & $47(31 \%)$ & $69(26 \%)$ & $22(33 \%)$ & $14(14 \%)$ \\
\hline Past History CVD & $30(14 \%)$ & $32(9 \%)$ & $24(17 \%)$ & $30(12 \%)$ & $6(9 \%)^{* *}$ & $2(2 \%)$ \\
\hline Current smoker & $100(46 \%)$ & $146(40 \%)$ & $72(48 \%)$ & $111(42 \%)$ & $28(42 \%)$ & $35(35 \%)$ \\
\hline 3+ Cardio-metabolic Risk Factors & $97(51 \%)$ & $170(54 \%)$ & $69(53 \%)$ & $130(57 \%)$ & $28(46 \%)$ & $40(47 \%)$ \\
\hline 4+ Cardio-metabolic Risk Factors & $46(24 \%)$ & $72(23 \%)$ & $32(24 \%)$ & $58(26 \%)$ & $14(23 \%)$ & $14(16 \%)$ \\
\hline
\end{tabular}

Data are $\mathrm{n}(\%)$.

Where $3+$ and 4+ CVD risk factors includes the 6 risk factors outlined in the above table.

$\mathrm{n}$ may vary due to missing data (see methods).

*Among all participants, proportions differed by gender for low-HDL $(p<0.001)$ and hypertension $(p=0.015)$.

${ }^{* *} p<0.05$ between Aboriginal and Torres Strait Islander participants (Pearson chi-square test). 


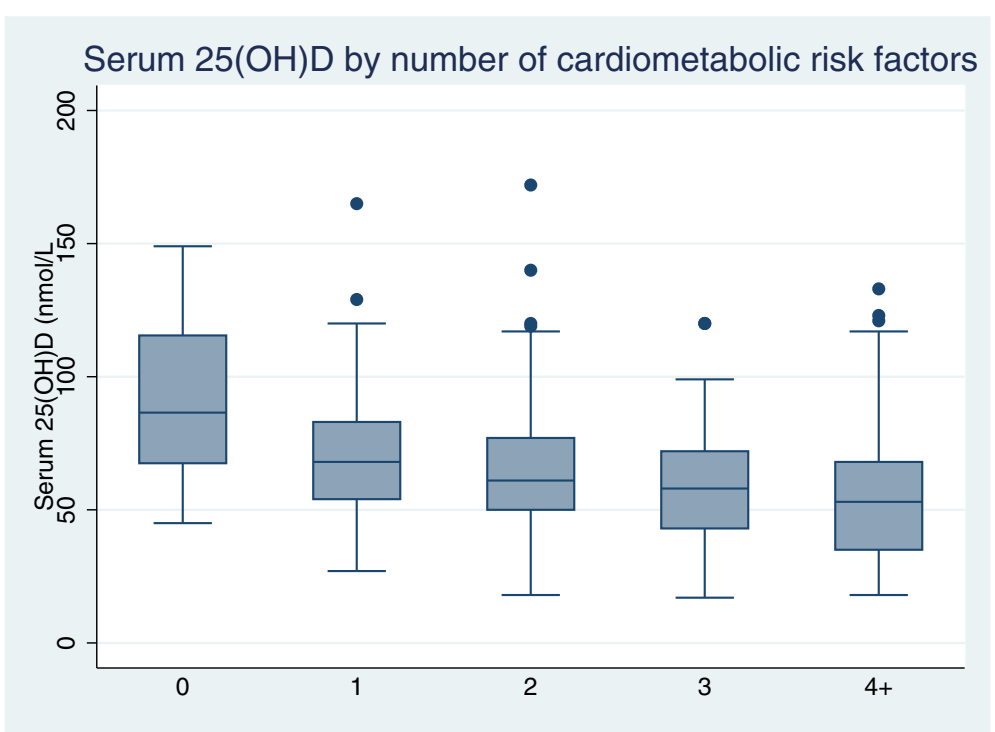

Figure 1 Serum 25(OH)D distribution in participants with increasing number of cardio-metabolic risk factors (central obesity, diabetes, low HDL-cholesterol, hypertension, current smoker, past history of CVD). The bars represent median and boxes represent interquartile range of serum $25(\mathrm{OH}) \mathrm{D}(\mathrm{nmol} / \mathrm{L})$, dots represent outliers; $n=24,87,127,149,118$ across groups with $0,1,2,3,4+$ cardio-metabolic risk factors, respectively; $\mathrm{p}<0.001$ for each category of cardiometabolic risk numbers compared to reference group of 0 risk factors.

Table 2 shows that $53 \%$ of all participants had at least three and $23 \%$ had at least four cardio-metabolic risk factors. Only 24 participants had nil risk factors. Levels of serum $25(\mathrm{OH}) \mathrm{D}$ fell with increasing numbers of cardio-metabolic risk factors (Figure 1). The study population was grouped on the basis of tertiles of $25(\mathrm{OH}) \mathrm{D}$ values $(\geq 72,53-71$ and $<53 \mathrm{nmol} / \mathrm{L})$. Compared to participants with serum $25(\mathrm{OH}) \mathrm{D}$ at the highest tertile $(\geq 72 \mathrm{nmol} / \mathrm{L})$, the odds ratio and $95 \%$ confidence interval (OR $(95 \% \mathrm{CI})$ ) of having $3+$ cardio-metabolic risk factors was 1.95 (1.20-3.16) and 4.00 (2.35-6.82) in participants with serum $25(\mathrm{OH}) \mathrm{D}$ in the middle and lowest tertiles, respectively, after adjustment for age, gender, ethnicity (Aboriginal or Torres Strait Islander), latitude and season. The strength of the association was reduced but still remained significant after inclusion of mGFR, troponin and urine ACR as covariates in the above model
[OR (95\% CI) 1.69 (1.02-2.81) for 25(OH)D 53-72 nmol/L and $3.04(1.71-5.40)$ for $25(\mathrm{OH}) \mathrm{D}<53 \mathrm{nmol} / \mathrm{L}]$.

Table 3 outlines the OR $(95 \% \mathrm{CI})$ for the association between each tertile of $25(\mathrm{OH}) \mathrm{D}$ and diabetes in different models. Compared to participants in the highest tertile of serum $25(\mathrm{OH}) \mathrm{D}(>72 \mathrm{nmol} / \mathrm{L})$, the risk of diabetes for participants in the lowest tertile $(<53 \mathrm{nmol} / \mathrm{L})$ was doubled [OR $(95 \%$ CI $) 2.15(1.10-2.18)$ ] after adjusting for cardio-metabolic risk factors in model 3.

\section{Discussion}

In this large cross-sectional study of 25(OH)D levels in Aboriginal and Torres Strait Islander Australians from Northern and Central Australia, we have reported three key findings. First, one third (31\%) of this Indigenous cohort had vitamin D deficiency (serum $25(\mathrm{OH}) \mathrm{D}<50 \mathrm{nmol} / \mathrm{L}$ ). Second, Indigenous Australian participants with 25(OH)D

Table 3 Risk of diabetes expressed as odds ratio according to tertiles of serum 25(OH)D levels

\begin{tabular}{|c|c|c|c|}
\hline \multirow[t]{2}{*}{$25(\mathrm{OH}) \mathrm{D} \mathrm{nmol} / \mathrm{L}$} & Model 1 & Model 2 & Model 3 \\
\hline & $n=592$ & $n=592$ & $n=489$ \\
\hline $\mathrm{T} 1(\geq 72)$ & Ref & Ref & Ref \\
\hline $\mathrm{T} 2(53-71)$ & $1.80(1.18-2.75)$ & $1.73(1.06-2.83)$ & $1.56(0.84-2.90)$ \\
\hline T3 $(<53)$ & $2.80(1.85-4.23)$ & $3.01(1.81-5.03)$ & $2.15(1.10-2.18)$ \\
\hline Covariates in the model & Unadjusted & $\begin{array}{l}\text { Age, gender, ethnicity } \\
\text { (Aboriginal or Torres Strait Islander), } \\
\text { season, latitude }\end{array}$ & $\begin{array}{l}\text { All co-variates in Model } 2 \\
\text { and waist-hip ratio, HDL-cholesterol, } \\
\text { mGFR, systolic BP, current smoker, } \\
\text { urine ACR }\end{array}$ \\
\hline
\end{tabular}


levels less than $50 \mathrm{nmol} / \mathrm{L}$ displayed a more adverse cardio-metabolic risk profile than those with 25(OH)D level greater than $50 \mathrm{nmol} / \mathrm{L}$. Third, serum 25(OH)D levels in the lowest tertile $(<53 \mathrm{nmol} / \mathrm{L})$ were independently associated with diabetes, and the association remained significant after adjustment for known cardio-metabolic variables.

To our knowledge, this is the first large study of $25(\mathrm{OH})$ $\mathrm{D}$ levels in adult Aboriginal and Torres Strait Islander Australians. We have reported a high percentage (31\%) of vitamin D deficiency in this cohort from Northern and Central Australia, regions closer to the equator than previous Australian studies. The median 25(OH)D level ( $55 \mathrm{nmol} / \mathrm{L}$ ) is similar to the mean $25(\mathrm{OH}) \mathrm{D}$ previously reported in a small study of 58 Aboriginal participants from South Australia (latitude 35 degrees south), of $56.8 \mathrm{nmol} / \mathrm{L}$ [12]. Of note, AusDiab, a nation-wide Australian population-based study, reported that 31\% of Australians had 25 $(\mathrm{OH}) \mathrm{D}$ levels $<50 \mathrm{nmol} / \mathrm{L}$, however only $0.9 \%$ of AusDiab participants identified as Aboriginal or Torres Strait Islander Australians [6]. High rates of vitamin D deficiency have been reported in other Indigenous populations internationally, including Aboriginal Canadian women (33\%) [18], New Zealand Maori and Pacific Islander New Zealanders (61\% and 69\% respectively, compared to $46 \%$ of New Zealanders of European descent) [19]. However, direct comparison is limited as key characteristics (latitude, age, BMI, co-morbidities) differ between cohorts.

Aboriginal and Torres Strait Islander participants in the current study with levels of $25(\mathrm{OH}) \mathrm{D}$ less than $50 \mathrm{nmol} / \mathrm{L}$ displayed a more adverse cardio-metabolic risk profile than those with $25(\mathrm{OH}) \mathrm{D}$ greater than $50 \mathrm{nmol} / \mathrm{L}$. Levels of $25(\mathrm{OH}) \mathrm{D}$ in the lowest tertile $(<53 \mathrm{nmol} / \mathrm{L})$ remained significantly associated with at least three cardio-metabolic risks independent of age, gender, ethnicity (Aboriginal or Torres Strait Islander), latitude, season, urine ACR, mGFR and troponin. Waist-hip ratio was used as the index of central obesity (rather than waist circumference) as it is a better discriminator of CVD risk across populations of different body build [20]. The relationship between 25(OH)D levels and cardio-metabolic risk factors observed in the current study is consistent with that described in large Australian and international observational studies, both cross-sectional [21] and longitudinal, for the outcome of cardiovascular events [5] and metabolic syndrome [2].

Low serum 25(OH)D was significantly associated with increased diabetes risk in this cross-sectional cohort. This is independent of other known cardio-metabolic variables (including waist-hip ratio, HDL-cholesterol, urine ACR, mGFR, blood pressure and cigarette smoking). A similar independent relationship between diabetes and $25(\mathrm{OH}) \mathrm{D}$ levels has been reported in other cross-sectional studies [11], and confirmed in prospective observational studies $[3,4]$. However, intervention studies have not clearly demonstrated efficacy of vitamin D supplementation against development of type 2 diabetes [22]. Several mechanisms have been proposed for the role of vitamin $\mathrm{D}$ in diabetes. Adequate serum 25(OH)D levels promotes synthesis of $1,25(\mathrm{OH})_{2} \mathrm{D}$ in extra-renal tissues. Improved beta-cell function by $1,25(\mathrm{OH})_{2} \mathrm{D}$ produced by pancreatic beta-cells, improved insulin sensitivity by $1,25(\mathrm{OH})_{2} \mathrm{D}$ in skeletal muscle, liver and adipose tissue, and systemic anti-inflammatory effects of $1,25(\mathrm{OH})_{2} \mathrm{D}$ reduce the risk of developing diabetes $[4,23]$. The odds ratio of the association between low vitamin $\mathrm{D}$ and diabetes decreased with addition of covariates (including season, latitude, and diabetes and cardio-metabolic risk factors) to the model. Data for physical activity and sun exposure were not available in the current study; inclusion of these data may have further attenuated the reported association, although data for central obesity and latitude were included.

High levels of vitamin D deficiency in Aboriginal and Torres Strait Islander participants in the current study may be related to darker skin pigmentation, reduced hours of sun exposure and/or change in physical activity levels from the hunter-gatherer to the sedentary indoor lifestyle. The change in dietary pattern from traditional (which was nutrient rich and included vitamin D-rich offal and a variety of marine species) to a Western pattern could also be a contributory factor, however dietary sources of vitamin D are often relatively low. The majority of Australians do not meet the recommended dietary intake of vitamin D [24] and vitamin D fortification is voluntary for dairy products (and mandatory only for edible oil spreads) in Australia.

Limitations of the current study include: its crosssectional design; data were not collected for physical activity, vitamin D supplementation, dietary sources of vitamin $\mathrm{D}$, skin pigmentation, sun exposure, time spent outdoors, sun protection behaviour; differences between Aboriginal and Torres Strait Islander participants for proportion with diabetes or CVD, latitude and season of blood collection. Season was categorised as the traditional four Australian seasons, as was used in the AusDiab study, although available data indicate that hours of sunlight per season vary less in tropical than in subtropical regions of this study [25]. Nevertheless, this is the largest study reporting 25(OH)D levels in Aboriginal and Torres Strait Islander Australians, a population at high risk of diabetes and CVD. Participants were from tropical and subtropical regions of Australia, regions where a significant proportion of Indigenous Australians reside, yet levels of $25(\mathrm{OH})$ $\mathrm{D}$ have not previously been reported among Indigenous Australians from these regions.

\section{Conclusions}

We have reported a high percentage of vitamin D deficiency among Aboriginal and Torres Strait Islander Australians 
from Northern and Central regions of Australia. Low level of $25(\mathrm{OH}) \mathrm{D}$ was associated with more adverse cardiometabolic risk profile and was independently associated with diabetes in this cross-sectional cohort. Further exploration of these findings is required in both longitudinal, observational and interventional studies.

\section{Additional file}

Additional file 1: Figure S1. Latitude of participants' usual place of residence. The Numbers inside the markers indicate the number of participants from each location, the letters indicate the location (from most northerly latitude) as follows: A, Thursday Island \& Torres Strait Islands; B, Elcho Island \& North Arnhemland; C, Darwin region; D, Kalumbaru; E, Katherine region; F, One Arm Point \& Broome region; G, Cairns \& Townsville; H, Halls Creek region; I, Lajamanu; J, Tennant Creek \& Barkly region; K, Port Headland region; L, Nyrippi; M, Alice Springs region; N, Brisbane; O, Geraldton region; P, Kalgoorlie region; Q, Perth region.

\section{Competing interests}

All the authors declared no competing interests.

\section{Authors' contributions}

$L M B, J H, P L, G R D J, A E, A S, A C, R J M, G J$, and KOD designed and conducted the eGFR study. LMB designed and performed the statistical analyses guided by ZL, GJ and KOD. ZL supervised laboratory measurement of $25(\mathrm{OH}) \mathrm{D}$. LMB drafted the manuscript with assistance from $\mathrm{KJ}$, and all authors contributed important intellectual content. All authors approved the final version for publication

\section{Acknowledgements}

Thanks to participants, study staff and investigators of the eGFR Study. Thanks to Roche Diagnostics for supplying the enzymatic creatinine reagent kits and Melbourne Pathology, Australia for the technical support for the analysis of enzymatic creatinine, 25(OH)D and high sensitive troponin T. The eGFR Study was funded by the National Health and Medical Research Council of Australia (NHMRC, Project Grant \#545202). The views expressed are those of the authors and do not reflect the views of NHMRC. Additional support was obtained from Kidney Health Australia, NHMRC \#320860, the Colonial Foundation, Diabetes Australia Research Trust, Rebecca L Cooper Foundation and SeaSwift, Thursday Island. LMB is supported by an Australian NHMRC Early Career Fellowship in Aboriginal and Torres Strait Islander Health Research (\#605837). JH is supported by NHMRC Scholarship \#490348, Rio Tinto Aboriginal Fund and the Centre of Clinical Research Excellence in Clinical Science of Diabetes, University of Melbourne. PL is supported by NHMRC Scholarship \#1038529. Cass holds a NHMRC Principal Research Fellowship \#1027204, and Hoy holds an NHMRC Australia Fellowship \#511081. Funding bodies had no role in the study design, in the collection, analysis or interpretation of data, in the writing of the manuscript or the decision to submit the manuscript for publication. The authors had full access to all of the data in The eGFR Study. eGFR Study Investigators: L Maple-Brown, P Lawton, W Hoy, A Cass, G Jerums, R Maclsaac, L Ward, M Thomas, K O'Dea, J Hughes, A Sinha, R MacDermott, G Jones, A Ellis, LS Piers, K Warr, A Brown, S Cherian, W Majoni.

\section{Author details \\ ${ }^{1}$ Menzies School of Health Research, Charles Darwin University, Darwin, Australia. ${ }^{2}$ Division of Medicine, Royal Darwin Hospital, Darwin, Australia. ${ }^{3}$ Melbourne Pathology, Melbourne, Australia. ${ }^{4}$ Department of Medicine, Monash University, Melbourne, Australia. ${ }^{5}$ University of South Australia, Adelaide, Australia. ${ }^{6}$ SydPath, St Vincents Hospital, Sydney, Australia. ${ }^{7}$ University of NSW, Sydney, Australia. ${ }^{8}$ Austin Health, Melbourne, Australia. ${ }^{9}$ Cairns Base Hospital and Diabetes Centre, Cairns, Australia. ${ }^{10}$ St Vincent's Hospital, Melbourne, Australia. ${ }^{11}$ University of Melbourne, Melbourne, Australia.}

Received: 21 March 2014 Accepted: 26 June 2014

Published: 16 July 2014

\section{References}

1. Australian Institute of Health and Welfare: The health and welfare of Australia's Aboriginal and Torres Strait Islander people, an overview 2011. Cat no: IHW 42. Canberra: AlHW; 2011.

2. Gagnon C, Lu ZX, Magliano DJ, Dunstan DW, Shaw JE, Zimmet PZ, Sikaris K, Ebeling PR, Daly RM: Low serum 25-hydroxyvitamin D is associated with increased risk of the development of the metabolic syndrome at five years: results from a national, population-based prospective study (The Australian Diabetes, Obesity and Lifestyle Study: AusDiab). J Clin Endocrinol Metab 2012, 97(6):1953-1961.

3. Gagnon C, Lu ZX, Magliano DJ, Dunstan DW, Shaw JE, Zimmet PZ, Sikaris K, Grantham N, Ebeling PR, Daly RM: Serum 25-hydroxyvitamin D, calcium intake, and risk of type 2 diabetes after 5 years. Diabetes Care 2011, 34(5):1133-1138.

4. Kayaniyil S, Retnakaran R, Harris SB, Vieth R, Knight JA, Gerstein HC, Perkins BA, Zinman B, Hanley AJ: Prospective Associations of Vitamin D With $\beta$-Cell Function and Glycemia. Diabetes 2011, 60(11):2947-2953.

5. Schottker B, Haug U, Schomburg L, Kohrle J, Perna L, Muller H, Holleczek B, Brenner $\mathrm{H}$ : Strong associations of 25-hydroxyvitamin D concentrations with all-cause, cardiovascular, cancer, and respiratory disease mortality in a large cohort study. Am J Clin Nutr 2013, 97(4):782-793.

6. Daly RM, Gagnon C, Lu ZX, Magliano DJ, Dunstan DW, Sikaris KA, Zimmet PZ, Ebeling PR, Shaw JE: Prevalence of vitamin D deficiency and its determinants in Australian adults aged 25 years and older: a national, population-based study. Clin Endocrinol 2012, 77(1):26-35.

7. Sambrook PN, Cameron ID, Cumming RG, Lord SR, Schwarz JM, Trube A, March LM: Vitamin D deficiency is common in frail institutionalised older people in northern Sydney. Med J Aust 2002, 176(11):560.

8. Kimlin M, Harrison S, Nowak M, Moore M, Brodie A, Lang C: Does a high UV environment ensure adequate vitamin D status? J Photochem Photobiol $B$ Biol 2007, 89(2-3):139-147.

9. Bendall A, de Costa C, Woods C, Howat P: Vitamin D levels in pregnant women booking for antenatal care in Far North Queensland. Aust New Zeal J Obstet Gynaecol 2012, 52(4):391-394.

10. Nowak M, Harrison SL, Buettner PG, Kimlin M, Porter D, Kennedy L, Speare R: Vitamin D status of adults from tropical Australia determined using two different laboratory assays: implications for public health messages. Photochem Photobiol 2011, 87(4):935-943.

11. Renzaho AM, Halliday JA, Nowson C: Vitamin D, obesity, and obesityrelated chronic disease among ethnic minorities: a systematic review. Nutrition 2011, 27(9):868-879.

12. Vanlint SJ, Morris HA, Newbury JW, Crockett AJ: Vitamin D insufficiency in Aboriginal Australians. Med J Aust 2011, 194(3):131-134.

13. Australian Bureau of Statistics. Census of Population and Housing Counts of Aboriginal and Torres Strait Islander Australians. ABS 2075.0. Australian Bureau of Statistics: Canberra; 2011.

14. Maple-Brown $\sqcup$, Lawton PD, Hughes JT, Sharma SK, Jones GR, Ellis AG, Hoy W, Cass A, Macisaac RJ, Sinha AK, Thomas MA, Piers LS, Ward LC, Drabsch K, Panagiotopoulos S, McDermott R, Warr K, Cherian S, Brown A, Jerums G, O'Dea K: Study Protocol-accurate assessment of kidney function in Indigenous Australians: aims and methods of the eGFR study. BMC Public Health 2010, 10:80

15. Maple-Brown $\amalg$, Hughes JT, Lawton PD, Jones GR, Ellis AG, Drabsch K, Brown AD, Cass A, Hoy WE, Macisaac RJ, O'Dea K, Jerums G: Accurate Assessment of Kidney Function in Indigenous Australians: The Estimated GFR Study. Am J Kidney Dis 2012, 60(4):680-682.

16. Lu ZX, Louey W, Hassan H, Liu A, Sikaris KA: How harmonised are the current commercial 25-Hydroxyvitamin D assays? Clin Biochem Rev 2012, 33:S22.

17. Alberti KG, Eckel RH, Grundy SM, Zimmet PZ, Cleeman Jl, Donato KA, Fruchart JC, James WP, Loria CM, Smith SC Jr: Harmonizing the metabolic syndrome: a joint interim statement of the International Diabetes Federation Task Force on Epidemiology and Prevention; National Heart, Lung, and Blood Institute; American Heart Association; World Heart Federation; International Atherosclerosis Society; and International Association for the Study of Obesity. Circulation 2009, 120(16):1640-1645.

18. Weiler HA, Leslie WD, Krahn J, Steiman PW, Metge CJ: Canadian Aboriginal women have a higher prevalence of vitamin D deficiency than nonAboriginal women despite similar dietary vitamin D intakes. J Nutr 2007, 137(2):461-465. 
19. Rockell JE, Skeaff CM, Williams SM, Green TJ: Serum 25-hydroxyvitamin D concentrations of New Zealanders aged 15 years and older. Osteoporos Int 2006, 17(9):1382-1389.

20. Maple-Brown L, Brimblecombe J, Connelly PW, Harris SB, Mamakeesick M, Zinman B, O'Dea K, Hanley AJ: Similarities and differences in cardiometabolic risk factors among remote Aboriginal Australian and Canadian cohorts. Diabetes Res Clin Pract 2013, 100(1):133-141.

21. Martins D, Wolf M, Pan D, Zadshir A, Tareen N, Thadhani R, Felsenfeld A, Levine B, Mehrotra R, Norris K: Prevalence of cardiovascular risk factors and the serum levels of 25 -hydroxyvitamin $D$ in the United States: data from the Third National Health and Nutrition Examination Survey. Arch Intern Med 2007, 167(11):1159-1165.

22. Avenell A, Cook JA, MacLennan GS, McPherson GC, group Rt: Vitamin D supplementation and type 2 diabetes: a substudy of a randomised placebo-controlled trial in older people (RECORD trial, ISRCTN 51647438). Age and ageing 2009, 38(5):606-609.

23. Giulietti A, van Etten E, Overbergh L, Stoffels K, Bouillon R, Mathieu C: Monocytes from type 2 diabetic patients have a pro-inflammatory profile. 1,25-Dihydroxyvitamin $D(3)$ works as anti-inflammatory. Diabetes Res Clin Pract 2007, 77(1):47-57.

24. Nowson CA, Margerison C: Vitamin D intake and vitamin D status of Australians. Med J Aust 2002, 177(3):149-152.

25. Australian Government Bureau of Meteorology. http://www.bom.gov.au/watl/ sunshine/ [Accessed 13 August 2013].

doi:10.1186/1758-5996-6-78

Cite this article as: Maple-Brown et al: Serum vitamin D levels, diabetes and cardio-metabolic risk factors in Aboriginal and Torres Strait Islander Australians. Diabetology \& Metabolic Syndrome 2014 6:78.

\section{Submit your next manuscript to BioMed Central and take full advantage of:}

- Convenient online submission

- Thorough peer review

- No space constraints or color figure charges

- Immediate publication on acceptance

- Inclusion in PubMed, CAS, Scopus and Google Scholar

- Research which is freely available for redistribution 